\title{
Nuestra Señora de
}

\section{Pontmain:}

\section{devoción mariana y nuevo}

catolicismo en Puebla,

\section{6-1914}

Sergio Rosas Salas ${ }^{1}$
sergiofrosas@yahoo.com.mx

ORCID: http://orcid.org/0000-0002-8092-8006
Our Lady of Pontmain:

marian devotion and new catolicism in

Puebla, 1876-1914

\section{Resumen}

El objetivo de este artículo es analizar la cultos. La hipótesis es que este culto fue difusión, desarrollo y declive del culto a Nuestra Señora de Pontmain en la ciudad de Puebla, para comprender la integración de nuevas devociones al catolicismo mexicano a finales del siglo XIX y discenir las causas de la popularidad de estos la expresión local de un Nuevo Catolicismo que sirvió como un elemento cultural que impulsó a clérigos y laicos a buscar nuevos mecanismos de presencia urbana y social del catolicismo en un contexto dominado por el liberalismo.

Palabras clave: Iglesia católica, Nuevo catolicismo, devoción, órdenes regulares, Puebla.

\section{Abstract}

The objective of this article is to analyze the diffusion, development and decline of the cult of Our Lady of Pontmain in the city of Puebla. Doing so, it tries to understand the way in which new devotions were integrated in Mexican Catholicism at the end of the 19th century and to discults. The hypothesis is that this the cult was the local expression of a New Catholicism that served as a cult element that impelled clerics and lay people to look for new mechanisms of urban and social presence of Catholicism in a context dominated by triumphant liberalism. card the causes of the popularity of these Keywords: Catholic Church, New Catholicism, devotion, regular orders, Puebla. Universidad Autónoma de Puebla, México.

Juan de Palafox 208, C.P. 72000, Centro, Puebla, Puebla, México. 


\section{Introducción}

El 17 de enero de 1871 los niños Eugenne y Joseph Barbadette, habitantes de la pequeña población de Pontmain, en el país del Loira, Francia, vieron "sobre el techo de una casa cercana [a la suya]... una grande y hermosa Señora que llevaba un vestido azul de mangas anchas y sembrado de estrellas, y que le bajaba hasta los pies... en la cabeza llevaba un velo negro y encima de él una corona de oro". La noche siguiente se repitió la aparición, frente a una muchedumbre que contempló a los niños pero fue incapaz de testificar el hecho. Conforme se acercaba la señora el cielo se iba llenando de estrellas, como su manto azul (Chávez, 1903, pp. 16-105). En febrero de 1872, estos acontecimientos fueron reconocidos como auténticas apariciones marianas por el obispo de Laval, Casimir Wicart, y poco después fueron aceptadas por el papa Pío IX. Había nacido el culto a Nuestra Señora de Pontmain o Nuestra Señora de la Esperanza, que completaba, con Lourdes y La Salette, una triada de apariciones en la Francia decimonónica que fueron reconocidas por la jerarquía eclesiástica para renovar el catolicismo ante la creciente secularización social (Porte, 2005).

En los años siguientes la devoción a Nuestra Señora de la Esperanza se expandió en el mundo católico. Llegó pronto a México: ya en 1876 la Imprenta Católica, patrocinada por el obispo Carlos María Colina, publicó en la Angelópolis un folleto informando sobre las apariciones. A partir de entonces y hasta 1914 se desarrolló un amplio culto a Nuestra Señora de Pontmain en la ciudad de Puebla, el cual expresó no sólo a través de impresos, sino con la creación de una capilla, una escuela, el fomento de una congregación que finalmente cambiaría su nombre y una amplia vida devocional. A pesar de su popularidad en la ciudad en las décadas de 1890 y 1900, esta devoción desapareció sin dejar rastro con los albores de la revolución mexicana. ${ }^{2}$

A la luz de estos elementos, el objetivo de este artículo es analizar la difusión, desarrollo y declive del culto a Nuestra Señora de Pontmain en la ciudad de Puebla, para comprender la forma en que se integraron nuevas devociones al catolicismo mexicano a finales del siglo XIX y discenir las causas de la (escasa) popularidad de estos nuevos cultos marianos en la sociedad porfirista. A partir de estos elementos, la hipótesis de este trabajo es que el culto a Nuestra Señora de Pontmain fue la expresión

\footnotetext{
2 Hasta donde he podido averiguar, el culto a nuestra Señora de Pontmain se limitó a la ciudad de Puebla, y no tuvo impacto en el resto de las parroquias diocesanas.
} 
local de un Nuevo Catolicismo que gracias al impulso del clero secular poblano no sólo integró cultos novedosos en el contexto local, sino que sirvió como un elemento cultual que impulsó a clérigos y laicos a buscar nuevos mecanismos de presencia urbana y social del catolicismo en un contexto dominado por el liberalismo triunfante que, sin embargo, permitió una amplia labor confesional a los creyentes (Ceballos Ramírez, 1991; Romero de Solís, 2006), posibilitando una activa participación de los católicos en la sociedad en el marco liberal (Bautista García, 2014).

Un concepto clave para este trabajo es Nuevo Catolicismo, tal como ha sido propuesto por Christopher Clark (2003), quien sostiene que ante la creciente secularización de las sociedades de fuerte raigambre católica durante el siglo XIX surgió una renovación católica que -entre otros elementos- se expresó a través de la proliferación de nuevas devociones populares, nuevas asociaciones religiosas, un creciente número de publicaciones confesionales y de profundos cambios en el papel del clero y laicos católicos en la sociedad a través de aspectos como la educación, prensa y asistencia social (Clark, 2003, pp. 11-14). Este Nuevo Catolicismo representó una propuesta de modernidad católica que, impulsada por los propios clérigos y laicos, buscaba que los creyentes fueran partícipes de las transformaciones de su tiempo en el contexto de amplias guerras culturales entre católicos y liberales -usualmente anticlericales- (Kaiser, 2003, pp. 58-76). Nuestra Señora de la Esperanza en Puebla es un símbolo devocional de este Nuevo Catolicismo en México; cuando el culto guadalupano se reforzó y los regímenes posrevolucionarios cerraron las puertas a esta propuesta de renovación católica el culto a Pontmain decayó. Esto ocurrió, ciertamente, por influencia del anticlericalismo revolucionario, pero en buena medida sucedió así por decisión de la propia jerarquía diocesana, la cual impulsó a Guadalupe como un culto nacional. Así pues, el trabajo también aporta elementos empíricos que demuestran que los cultos impulsados por el clero secular a fines del siglo XIX tenían importantes fines de reforma eclesiástica y no siempre respondían a un interés especialmente marcado del conjunto de los fieles en esa devoción -como ocurrió con la coronación de la virgen de la Soledad en Oaxaca en 1909(Wright-Rios, 2009, pp. 79-82).

Sin embargo, en el porfiriato, el culto floreció en Puebla. Como sugiere esta investigación, Pontmain expresó el desarrollo de un Nuevo Catolicismo en Puebla, pues condensó tres pilares de este revivamiento religioso: nuevos cultos, (nueva) educación confesional y la creación de nuevas congregaciones (femeninas) e inmuebles. A través de estos elementos, los católicos poblanos propusieron vías alternas de modernidad que buscaron integrar el ejercicio de la ciudadanía (liberal) con el cato- 
licismo. ${ }^{3}$ En ese sentido, este artículo discute la idea planteada en otros trabajos respecto a que las apariciones marianas exportadas del país galo tenían como objetivo ser un ataque a la modernidad y una advertencia a los fieles sobre las amenazas que ésta traía para la sociedad (Moreno Chávez, 2013, pp. 31-40). Antes bien, considero que el culto angelopolitano a Pontmain representa una búsqueda del clero, y en particular de los canónigos angelopolitanos, para integrar su fe al mundo liberal de fines del siglo xIX y ofrecer como alternativa una modernidad católica, en tanto aprovechaba varios de los principios garantizados en la constitución mexicana -como el derecho de propiedad y el impulso a la educación-. El artículo está dividido en dos apartados. En el primero exploro la forma en que se difundió el culto en Puebla y rastreo el culto que se le dio cotidianamente a la virgen; en el segundo analizo la construcción del templo de Pontmain y el desarrollo en torno a él de una escuela y una congregración católicas. Las fuentes de fondo antiguo que se refieren fueron consultadas en la Biblioteca Palafoxiana y en la Biblioteca José María Lafragua de la Benemérita Universidad Autónoma de Puebla. Es de lamentarse la imposibilidad de acceder a fuentes de archivo, pues desafortunadamente los archivos de aquella arquidiócesis se encuentran cerrados a la consulta. En ese sentido, este trabajo se basa en documentos impresos, dejando para ulteriores investigaciones analizar su presencia en las parroquias o en el gobierno diocesano.

\section{El impulso a una devoción y su recepción en México}

Las apariciones de Nuestra Señora de la Esperanza fueron difundidas en México ya en 1876, cuando la Imprenta Católica de Puebla publicó Nuestra Señora de la Esperanza de Potmain, un folleto de 69 páginas que sirvió para propagar el culto en el país. En realidad, se trataba de un resumen de la obra del Conde de Lafond, Salette, Lourdes, Pontmain; fue elegida esta sección toda vez que "las dos primeras apariciones... son ya muy conocidas en esta república". La lectura era importante porque, como Francia, la Iglesia y el catolicismo vivían en México momentos difíciles por el embate de la "funesta apostasía" (Lafond, 1876, pp. 2 y 67). Se trata de un texto que narra con detalle la historia de las apariciones, y a partir de la oración mariana el texto va a insistir en la importancia de la oración

La "modernidad" de los actores católicos durante el porfiriato ha sido ya explorada por historiadoras como O’Dogherty Madrazo (2003), García Ugarte (2010) y Bautista García (2012). 
para salvaguardar la fe en nuestro país, siguiendo el ejemplo galo. El traductor, quien firmó con las iniciales J.M.B, parece haber sido el cura de San Andrés Chalchicolula, una parroquia al oriente del obispado de Puebla que estaba interesado en difundir la obra en un contexto de una amplia publicación de obras apologéticas en la Angelópolis. ${ }^{4}$

Este primer elemento es importante, pues de hecho la difusión de la obra del conde de Lafond en Puebla fue parte de un importante esfuerzo editorial iniciado en aquella ciudad durante la república restaurada, siguiendo una trayectoria nacional a través de la cual los católicos, derrotados con el II Imperio, se refugiaron en las letras, traducciones y publicaciones periódicas para sostener su fe (Adame Goddard, 1991, passim). En Puebla, por ejemplo, desde 1868 y a instancias del obispo Carlos María Colina el editor Isidoro Boclar empezó a publicar La Revista Eclesiástica, periódico católico semanal que difundió las noticias del obispado de Puebla y sobre todo publicó artículos de apologistas y polemistas franceses, entre quienes destacaron Pierre Leroux y Gaume (Revista, 1868, passim). A ello hay que sumar, por citar un par de obras editadas el mismo año que el texto del conde de Lafond, la edición de algunas obras que parecen haber circulado ampliamente, como El Estado sin Dios de Augusto Nicolás (1876), o el Estudio sobre la francmasonería de monseñor Dupanloup (1876), los más importantes publicistas católicos de la Francia de la restauración. A través de estas ediciones los letrados católicos poblanos, cobijados e impulsados por el obispo y el cabildo eclesiástico, buscaron ofrecer textos polémicos de defensa de la Iglesia y su posición social ante el liberalismo triunfante, y subrayaron la importancia que la fe y la práctica religiosa tenía en los vínculos sociales.

Amén de lo anterior, ya el caso de Agustín Rivera en Lagos ha mostrado que los textos franceses fueron publicados y citados en México buscando conciliar el progreso natural con la religión (Carbajal López, 2017, pp. 295-340), la "verdadera civilización" para utilizar el término de Bulnes. Así pues, tenemos que a través de la prensa los católicos poblanos buscaron canales de difusión de su creencia y (nuevos) espacios para el catolicismo en la sociedad liberal, un aspecto central en el nuevo catolicismo, fuera a través de la búsqueda de puentes de conciliación o lo que es más, a través de posturas abiertamente apologéticas. co de San Andrés Chalchicomula por el obispo de Puebla Carlos María Colina en 1868, pero no sólo coinciden las dos primeras iniciales, J.M., sino que el autor refiere que ha estado reflexionando sobre la traducción de Lafond y la devoción de Pontmain en Chalchicomula. 
Esta última función tenía el texto del conde de Lafond sobre Pontmain: abrir desde la apologética un espacio a la religión en el mundo contemporáneo a partir de una aparición mariana contemporánea, polemizando con las posturas más radicales que luchaban abiertamente contra la fe. En el contexto mexicano, además, se buscó vincular a Pontmain con Guadalupe, la aparición mexicana por excelencia. Vamos a repasar la historia de Nuestra Señora de la Esperanza desde la perspectiva de Lafond. Durante la guerra franco-prusiana -entre 1870 y 1871, que concluyó con la anexión de Alsacia y de Lorena al I Reich-en un apacible pueblecillo llamado Pontmain, "pequeño poblado de 500 almas... profundamente cristiano" vivía la familia Barbedette, "compuesta de padre, madre y tres santos varones" (Lafond, 1876, pp. 11-13). La noche del 17 de enero de 1871 el niño Eugenio "a veinte pies cerca del centro y sobre el techo de la casa, percibió una Señora bellísima", ataviada a la manera de María Inmaculada. Otro de los niños, José, vieron a la señora. Los adultos, como suele ocurrir en estos casos, no pudieron ver la aparición: el padre fue incapaz, la criada Luisa y peor aún, el cura, Monsieur Guerin. Sin embargo, dos niñas vieron la aparición: Francisca Richer, de once años, y Juana María Lebosse, de nueve.

Según el testimonio de los niños, la Virgen estaba rodeada de cuatro cirios: dos a la altura de sus rodillas y dos a la altura de sus hombros. Después de un rato los reunidos empezaron a rezar el rosario, con lo que la Virgen creció al doble, alcanzando el tamaño de la gente. Ante los niños, la virgen escribió con estrellas "priez, mes enfants" (recen, niños míos). Al otro día, con los prusianos a la puerta de la población, la Virgen apareció y escribió, siempre con estrellas: Dieu vous exaucera en peu de temps (Dios los escuchará pronto), y al otro día Mon fils se laisse toucher (Mi hijo se deja tocar; se puede alcanzar). La aparición fue recordada por sus publicistas porque era la primera vez en la historia que se hacía visible "una inscripción celestre en los aires" después del milagro de Constantino. Pero el milagro no acabó ahí: después de haber escrito su último mensaje, apareció en el cielo una cruz roja, de 60 centímetros, que tenía un Cristo del mismo color. La Virgen lo tomó y se lo presentó a los niños: "el crucifijo sangrante [diría más tarde el conde de Lafond] recordaba los pecados de la Francia que habían crucificado nuevamente al Cristo, y atraído sobre nosotros la cólera divina" (Lafond, 1876, p. 33). Al día siguiente de la aparición los prusianos se retiraron de Laval, y diez días después se firmó un armisticio que fue el preludio de la paz. Las apariciones fueron reconocidas por el obispo de Laval, Monseñor Wicart, el 2 de febrero de 1872, aceptando que hubo cuatro videntes: los niños Eugenio y José Barbedette, y las niñas Francisca Richer y Juana María Lebossé. 
¿Cuál era la moraleja que el conde obtenía de esta historia? Según la traducción publicada en Puebla en 1876, la aparición de Pontmain mostró en primer lugar que "la Reina de Francia ha[bía] tenido piedad de su reino". En 1875, tan sólo cuatro años después de la aparición, se calculaban ya que cada año llegaban 100000 peregrinos al año. En el lugar de la aparición se levantó "una columna con la imagen como la vieron los niños, a la que llamaron Madre de la Esperanza"; en esos años se estaba empezando a edificar una iglesia. El himno que se cantaba decía "Madre de Santa Esperanza / vednos recurrir a Vos / proteged a nuestra Francia / y rogad, rogad por nos" (Lafond, 1876, p. 45). Como se ve, un primer elemento fomentado por los publicistas franceses era la protección de la patria y más, de los católicos en los contextos bélicos o de confrontación. Era, además, la promesa de la paz final. Así, Lafond concluye diciendo que Pontmain significaba "la Esperanza del triunfo y de la paz". Por otra parte, el conde concluía señalando que la aparición -con la de La Salette en 1846 y Lourdes en 1858- mostraba que se cumpliría pronto la profecía de San Vicente Ferrer respecto al inminente reinado de María, por lo que concluía: "el siglo xIX es el siglo de María, es el siglo de Pío IX. Si, este es el reinado de nuestra Madre... pero en Francia es, sobre todo, donde resplandecen" (Lafond, 1876, p. 56).

¿De qué modo este panegírico podía trasladarse a otro país? En otras palabras, ¿cómo se afianzó en México un culto que nació con un fuerte sentimiento nacionalista y en el contexto de una guerra europea? El traductor del tratado, J.M.B., tuvo un papel fundamental para integrar la aparición francesa en las preocupaciones del contexto mexicano. Además de apuntar al calce que México ofrecía un "espectáculo desgarrador... a los ojos de los verdaderos católicos", el traductor señaló como su motivación para verter al español "el bello relato de Monsieur Lafond" que mientras lo leía "hacía involuntariamente comparaciones entre esta desdichada Patria y la Francia" (Lafond, 1876, p. 67). Por tanto, concluyó: "la Francia ha pasado por terribles pruebas, pero ha comenzado a orar, y sólo el principio de sus ruegos ha bastado para atraerle la presencia de la Reina del Cielo que, complacida con las preces de una pequeñísima aldea, manifestó cuan poderosa es la oración". Y si así ocurrió "en el lugarejo de Pontmain, ¿por qué México, si quiere orar, no alcanzará que se le apliquen por la Divina Misericordia las otras palabras de la augusta virgen: Dios os escuchará dentro de poco tiempo?". En ese sentido, para el anónimo traductor, Pontmain mostraba el poder de la oración y sobre todo, mostraba que la Virgen podía salvar de las peores penurias y persecuciones a los países donde los católicos rezaban, como podía ocurrir en el México gobernado "por funesta apos- 
tasía". México se convertía así, como Francia en Europa, en un baluarte del catolicismo en América.

El traductor fechó desde enero de 1874 una plegaria que sintetizaba lo anterior, y además tenía un novedoso elemento que vale la pena retomar:

Virgen, que anunciais bonanza / a las Galias en Pontméen [sic], / dad a México esperanza / que vuestro reino es también.

Acordaos, oh madre amada! / que esta patria en voz confía, / esta patria, hoy desolada / por funesta apostasía.

Acordaos que, diligente, / Tepeyac, produjo rosas / a vuestra voz obediente, / en sus lomas pedregosas....

Esto México protesta, / con doliente corazón / y sus pecados detesta: / alcanzad su salvación (Lafond, 1876, p. 67).

Como se puede ver, la vinculación entre Nuestra Señora de Pontmain y México se concretó a través de dos elementos desde la década de 1870, gracias a sus publicistas en este país: a través de la oración como un remedio contra la guerra, que en el caso de México se refería a una guerra contra la Iglesia -bajo la certeza de que Dios escuchará a los rezantes- y a través de la equiparación entre Pontmain y Guadalupe. Quiero resaltar este último aspecto, pues es importante tener presente que el aprovechamiento de la aparición en el Tepeyac contribuyó a afianzar un nuevo culto en México.

En el caso que nos interesa, la equiparación entre la virgen del Tepeyac y la virgen de Pontmain fue el hecho mismo de la aparición y con ella su posibilidad de ser un factor de conversión social. En efecto: si bien México ahora vivía "una funesta apostasía", como señaló el traductor J. M. B., gracias a Guadalupe hace muchos años había "produ[cido] rosas / a vuestra voz obediente, en sus lomas pedregosas". En última instancia, el elemento común entre Guadalupe, México, Pontmain y Francia era que ambas vírgenes se habían aparecido en dos países católicos que enfrentaban un periodo de (re)conversión y por supuesto, de irreligión. La oración podía salvar a México como había salvado a Francia de males incluso peores, pues como en Francia, la virgen misma se había aparecido en suelo americano para prometer paz... como la virgen de Pontmain. Este elemento es importante, pues la vinculación de Nuestra Señora de la Esperanza con Guadalupe permitió afianzar el culto y de hecho llevó en Puebla a una imbricación entre ambas devociones, según veremos más adelante.

Así pues, un segundo elemento de la difusión de la obra y devoción gala es que sirvió a los católicos para defender las apariciones en el Tepeyac ya en 1896, después de que el historiador Joaquín García Icaz- 
balceta publicara la famosa carta donde informa al arzobispo de México que no había pruebas históricas sobre los sucesos de Tepeyac en 1531. Firmando con sus iniciales, Gabino Chávez escribió un impreso titulado La aparición guadalupana demostrada por los últimos ataques de sus enemigos. Observaciones sobre la carta atribuida al Señor Don Joaquín García Icazbalceta, que como su título lo indica, quería rebatir los hallazgos del historiador para demostrar la aparición guadalupana. Entre los múltiples argumentos con los que Chávez rebate a Icazbalceta, uno de ellos apuntó:

San Pablo nos da la razón de esta economía que parece repugnar a la razón humana. "para que ningún hombre se gloríe delante de Dios", es decir, para que se atribuyan a Dios, y no a los hombres, meros instrumentos, los grandiosos resultados de sus obras. Y he aquí por qué, Dios elige en estos casos a los pobres, a los ignorantes, a los plebeyos. Así eligió en la Salette dos pobres pastorcillos, niños de poca edad, y en Pontmain, niños de aldea, y en la célebre Lourdes a una niña pobre, raquítica, plebeya e ignorante; y en el Tepeyac a un pobre indio, neófito, ignorante, despreciable, para confundir a los sabios que aún no acaban de comprender, en pleno cristianismo, esta ley perpetua de la acción divina (Chávez, 1896, p. 28).

Chávez concluye:

Las apariciones, pues, verificadas en nuestro siglo en la Salette, Lourdes, Pontmain en Francia, Marpinghen en Alemania, y otras menos conocidas, como hechas todas a pobres, pastores o campesinos, vienen a confirmar la Aparición guadalupana, y la pobreza, ignorancia y sangre indígena de Juan Diego, consideradas a los ojos de la fe, y bajo las enseñanzas de la Teología mística y de la Sagrada Escritura, dan a la escena del Tepeyac una verosimilitud que raya en la certidumbre (Chávez, 1896, p. 28).

La vinculación no podía ser más evidente: según Chávez, la aparición de Pontmain confirmaba la aparición guadalupana aunque hubiera ocurrido trescientos años antes, y al mismo tiempo, la historia de Juan Diego ampliamente conocida por los católicos mexicanos aseguraba la aceptación de la aparición de Pontmain en México -como de La Salette y Lourdes. La aparición mariana es pues, y vale la pena repetirlo, un vínculo entre naciones. El hecho es importante, además, porque como el título lo indica ocurrió en un momento de grandes debates en torno a la apa- 
rición guadalupana, producto de la coronación de la imagen en 1895. En ese sentido, ya la defensa de Guadalupe y su equiparación con Pontmain era un acto de apología católica en México durante la década de 1890 (Bautista García, 2006).

El apologista mexicano Gabino Chávez no sólo utilizó la historia para entrar en debates eruditos en torno a Guadalupe, sino que se dedicó a difundirla entre las escuelas católicas. Ya en 1893, el presbítero Gabino Chávez escribió, por iniciativa del obispo de Querétaro Rafael Camacho, El amigo católico de las niñas. Lecciones instructivas y edificantes, morales, doctrinales y recreativas, para el uso de las escuelas católicas. Entre las primeras historias estaba la de Nuestra Señora de Pontmain, "una reciente historia, tan bella como verdadera", que revelaría "cuánto quiere a los niños la Madre de Dios, la inmaculada Virgen María". Así pues, las escuelas católicas fueron uno de los principales espacios de difusión de la historia de Pontmain, gracias al fomento episcopal -además de Camacho, hay una licencia y una aprobación dentro del libro de Francisco Melitón Vargas, obispo de Puebla y anterior primado de Colima- y a la labor de publicistas como Gabino Chávez, quien junto con el "anónimo presbítero" de Chalchicomula difundieron la historia de Pontmain-. De hecho, la historia que va contando Chávez no es otra que la del conde de Lafond (Chávez, 1903, pp. 16-105).

Lo interesante es que la historia sirvió a Chávez para ir dejando enseñanzas morales a las niñas. Así, por ejemplo, Pontmain mostró que los niños Eugenio y José eran "muy buenos y dóciles con sus padres", como debían de ser los niños, y no abandonaban la escuela "a pesar del mucho frío y del mal tiempo". En la segunda semana de la historia, por ejemplo, las niñas aprendían gracias a Eugenio que la Virgen quiere sobre todo a los niños, pues "la gente grande, aunque piadosa y buena no la ve, sólo los niños no dejan de mirarla". Pero había que corresponder con deseos de estar con la Virgen. Chávez insistirá: "¡Qué ardiente deseo de estar con María muestra Eugenio! Si pudiera, dice, se estaría allá siempre, sin moverse. ¿Os estáis quietas sin moveros en la iglesia, y deseáis estar largo rato con María Santísima, rezándola y alabándola?" Más tarde enseñará que hay que rezar el rosario todos los días, y para cerrar, concluirá: "Por aquí veréis niñas, cuan buena es nuestra dulce Madre, y cuántas cosas nos consigue con Dios, y cuan bueno es rezarle su rosario y sus letanías, pues a los gritos tan repetidos que allí le damos no es posible que permanezcan duras sus entrañas, ni sordos sus oídos maternales. Invocadla, pues, tomadla por Madre, ser fieles en sus prácticas y no olvidéis consagrarle de un modo especial el día del sábado". En suma, el cura Chávez aprovechó la historia de la aparición francesa para enseñar a la 
infancia la importancia de una práctica religiosa cotidiana, insistiendo en la oración como método para perseverar en la fe. Chávez, pues, aprovechó la aparición mariana para reforzar la importancia del culto externo, en línea con los intereses generales de la época que aprovecharon las nuevas devociones para enfatizar la presencia del catolicismo en la sociedad, otorgando nuevos elementos cultuales a los católicos (Díaz Patiño, 2016).

La historia de Chávez, pues, sirvió para fomentar la devoción a Nuestra Señora de Pontmain en la década de 1890. El método surtió efecto: por lo menos en Puebla, desde aquella década se desarrolló un culto a esta devoción que se expresó no sólo en impresos, sino en la construcción de un templo, el fomento de una escuela, la creación de una congregación y finalmente, en el amplio desarrollo de un culto local.

\section{Pontmain y nuevos mecanismos de presencia católica en Puebla}

La promoción del culto a Nuestra Señora de Pontmain encontró en Puebla un terreno fértil. A partir de una capilla dedicada a esta advocación se desarrollaron tres elementos que permitieron al clero poblano mostrar su presencia en la ciudad: una amplia y cotidiana vida devocional, la formación de una escuela confesional y la fundación de una nueva congregación religiosa. Estos tres elementos, fundamentales en la formación de un Nuevo Catolicismo, nos permiten mostrar que el culto a Pontmain en Puebla permitió una renovada participación del clero secular y de mujeres seglares en la sociedad local, quienes a partir de una iniciativa clerical fomentaron un culto que quedó ligado a la posibilidad -otorgada por el régimen liberal de Porfirio Díaz- de participar activamente en la vida pública, social y educativa de Puebla en las décadas de 1890 y 1900. Se trató, pues, de un culto impulsado en Puebla por iniciativa eclesiástica con apoyo de un grupo de mujeres que, acordes con las renovaciones vividas entre los creyentes durante el siglo XIX, decidieron no sólo consagrarse a Dios sino prestar un servicio útil a la población. Por supuesto, la vía elegida fue la educación.

La primera noticia que tenemos sobre la fundación de una capilla dedicada especialmente a Nuestra Señora de la Esperanza o de Pontmain en Puebla data de 1884, como iniciativa personal del sacerdote diocesano Luis de la Torre (Memorias, 1984, p. 31). Luis Gonzaga de la Torre y Baeza nació en 1833 en la ciudad de Puebla, y tras formarse en el Seminario Palafoxiano se ordenó sacerdote en 1861, dedicándose desde entonces al servicio de la catedral, donde fue padre sacristán y más tarde apuntador del Cabildo, además, enseñó latín en su alma mater. A partir de 1886 se 
consagró a atender hasta su muerte en 1911 la congregación y el colegio que quedarían ligados a la devoción de Pontmain, y que aún lo recuerdan como su fundador (Memorias, 1984).

Si bien desde la década de 1860 este eclesiástico había decidido impulsar la construcción de un templo dedicado al Corazón de María en la plazuela del Parral -en el extremo suroeste de la ciudad, una zona especialmente afectada por la intervención francesa y el sitio de Puebla de 1863-, hasta la década de 1880 se abrió al culto un "oratorio provisional continuo a la parte de ella que se está edificando poco a poco" (Mendizábal, 1894, p. 74). Este hecho se concretó en 1884, cuando Luis de la Torre abrió una capilla junto al templo, en lo que posteriormente serían las instalaciones del colegio. El espacio, "de una sola pieza, larga, angosta, y con techo de vigas muy bajo", fue dedicado al Corazón de María, pero años más tarde fue nombrado como el Oratorio de Pontmain, ubicado en la que es hoy la segunda privada de la 7 poniente, número 701, y que permaneció en culto público varios años teniendo como titular precisamente a Nuestra Señora de la Esperanza (Carrión, 1897, I, p. 403). ${ }^{5} \mathrm{La}$ elección de este último culto parece haber sido producto de una devoción personal: en 1884, los hermanos Sebastián y Leonor Tapia -seglares que habitaban cerca del templo de San Roque, a dos calles de catedral- decidieron obsequiar las imágenes para la capilla, que resultaron ser las más importantes de la segunda mitad del siglo XIX: el Sagrado Corazón de Jesús, el Inmaculado Corazón de María, y Nuestra Señora de Pontmain (Díaz Patiño, 2016, passim). Además, entregaron bultos de la Virgen de los Dolores, un San Luis Gonzaga, una imagen del Señor Ecce Homo y finalmente un Niño Dios. La capilla fue bendecida solemnemente el 22 de mayo de 1884, oficiando la primera misa el obispo de Puebla José María Mora y Daza, asistido por Luis de la Torre. Si bien en primera instancia se dedicó al Corazón de María, en 1891 se dedicó a la virgen de Pontmain y su imagen presidió el Oratorio (Memorias, 1984, pp. 31-32).

A partir de entonces se desarrolló una amplia vida devocional en torno al oratorio, que mostró la vitalidad ya no sólo del culto a Nuestra Señora de Pontmain, sino de la vida cultual católica en Puebla. Los ciclos devocionales de las dos décadas siguientes siempre incluyeron la presencia del oratorio de Pontmain como un espacio de culto en la ciudad. Si bien a partir de estas menciones es difícil medir el impacto del culto en la población, es evidente que el clero secular tuvo especial interés en fomentar esta devoción. Para tener sólo algunos ejemplos, podemos señalar los

5 Se reservó al Corazón de María como la advocación del templo principal, completado años más tarde. 
ciclos devocionales de 1900. Aquel año, en el oratorio había misa diaria y ocurrían varias celebraciones especiales a lo largo del año. El 17 de enero, aniversario de las apariciones, por ejemplo, se celebró la "gran fiesta anual a Nuestra Señora de Pontmain", con una gran verbena popular; los festejos siguieron el siguiente domingo, 20 de enero, celebrándose vísperas y maitines. Al día siguiente, 21 de enero, el templo festejó la segunda fiesta más importante para el oratorio, pues se celebró ahí la misa a San Luis Gonzaga, con una comunión general. Como era costumbre en aquellos años, los oficios de la Semana Mayor sólo se celebraron en algunos templos de la ciudad: además de la Catedral, se llevaron a cabo en las parroquia del Santo Ángel y San Marcos, y en los templos de Belén, San Felipe Neri, San Luis, Los Gozos y los Oratorios de la Misericordia y Pontmain (Mendizábal, 1900, pp. 5-6).

En 1904, por ejemplo, se mantenía una intensa vida devocional en torno al templo. Además del aniversario de las apariciones, el 12 de junio se inició el novenario a San Luis Gonzaga en Pontmain, y el 20 y 21 del mismo mes se celebraron varias misas que culminaron con una "función solemne a San Luis Gonzaga en el oratorio de Pontmain". Al día siguiente, el 22 de junio había otro gran festejo, pues era de los templos poblanos donde se hacía fiesta solemne por el Sagrado Corazón de Jesús. En julio, además, se celebraba el mes de San José, que también se realizaba en la parroquia de San José -la más antigua de la ciudad después del Sagrario) y en los templos de San Juan de Dios y San Ramón. El 16 de junio, finalmente, se hacía una misa solemne a Nuestra Señora del Carmen (Mendizábal, 1904, pp. 29-77). Todavía en 1909 encontramos noticias sobre el culto en el oratorio: en 1909 se anunció con bombo y platillo la celebración del 17 de enero -como de hecho ocurrió a lo largo de la primera década del siglo $\mathrm{xx}-\mathrm{y}$ en los meses siguientes la capilla participó en el Jubileo Circular de 40 horas para la ciudad, correspondiéndole los días del 18 al 21 de junio (Mendizábal, 1905, p. 31; Mendizábal, 1908, p. 28; Mendizábal, 1909, pp. 26-53). El último almanaque en que se anuncia la fiesta es, precisamente, 1910, cuando se celebró el aniversario de las apariciones el 17 de enero y la función solemne se realizó el 23 de enero; ese año, además, el oratorio celebró como era costumbre la función a San Luis Gonzaga el 21 de junio. El cura encargado del seminario seguía siendo don Luis de la Torre, quien murió en aquel mismo lugar al año siguiente, en julio de 1911 (Mendizábal, 1910, pp. 21-43; Leicht, 1999, p. 295).

Las evidencias disponibles hasta el momento demuestran tres elementos que me interesa destacar. En primer lugar, que el culto a Nuestra Señora de Pontmain en Puebla se desarrolló gracias a un grupo de sacerdotes seculares poblanos y un grupo de laicos poblanos, mayormente 
mujeres, quienes en las décadas de 1880 y 1890 impulsaron a través de la imagen y el culto cotidiano a la virgen de Pontmain en la ciudad, esfuerzo que se vio plasmado con la consagración del oratorio a este culto en 1891. En segundo lugar, me interesa destacar que la construcción del templo dio paso al desarrollo y difusión del culto a Pontmain, el cual fue posible ciertamente por los afanes del presbítero Luis de la Torre, pero también en buena medida gracias al florecimiento del catolicismo en la ciudad, gracias a la posibilidad de ejercer el culto público en los templos durante el porfiriato. Por último, hay que destacar que el ocaso de la devoción a la virgen de Pontmain, cuyos registros se pierden en la década de 1910 se debe en buena medida a la muerte de su principal promotor y al crecimiento de la devoción a la virgen de Guadalupe -impulsada por el arzobispo de Puebla Ramón Ibarra.

En ese sentido, es posible afirmar dos elementos acerca del fin del culto a Pontmain en Puebla. En primer lugar, se evidencia que el fin de su culto está ligado a la muerte o cambio de sus promotores -lo que evidencia, por lo demás, poco arraigo entre la población. En segundo lugar, las pruebas permiten aseverar que el declive de la devoción francesa se debió más a una transformación al interior del propio catolicismo más que a una influencia externa a él-aunque ciertamente, el anticlericalismo revolucionario afectó el culto al cerrar el colegio en 1914, como veremos a continuación.

Lo anterior es evidente si repasamos la historia de la escuela y la congregación que surgieron en torno al oratorio de Pontmain, impulsados también por el presbítero Luis de la Torre. En 1884, el mismo año que se fundó el Oratorio, el obispo Mora y Daza inauguró oficialmente el Colegio Católico de Instrucción Primaria en un edificio anexo a él. Como en el caso del templo, la escuela fue producto de una iniciativa compartida entre de la Torre, como miembro del clero secular, y un grupo de mujeres consagradas a la vida religiosa y la educación, y tenía algunos antecedentes. En conjunto con el padre de la Torre, en 1882 la señorita Rosario Ávila Campos decidió la fundación de una escuela de primeras letras para niñas huérfanas y pobres que empezó a funcionar al año siguiente. En conjunto con la señorita Dolores Oropeza y Neve se dedicó a enseñar a leer, escribir y contar a niñas de la ciudad, además de instruirlas en doctrina cristiana "y en los principios morales de conducta" (Memorias, 1984, p. 28). El día de la inauguración, el obispo Mora y Daza señaló: "muchas niñas aprenderán aquí a construir una sociedad más feliz que la de hoy. Esperamos que las niñas que se formen en esta escuela, sean no sólo buenas cristianas que es lo principal, sino buenas amas de casa, que es también muy importante" (Memorias, 1984, pp. 36-37). Como la capilla, la 
escuela fue dedicada a la Virgen de Pontmain, pues según de la Torre, en ella, también Nuestra Señora de la Esperanza, ponía "su esperanza total para la realización de la obra" (Memorias, 1984, p. 37).

La escuela de Nuestra Señora de Pontmain formó parte de una red más amplia de escuelas católicas que surgió en Puebla en aquellos años. A través de ellas, la Iglesia católica buscó nuevos elementos de presencia en la sociedad, aprovechando los espacios que había abierto el régimen de Porfirio Díaz. La presencia de las escuelas católicas en ciudades como Puebla fue más cualitativa que cuantitativa, pero es importante señalar que esta presencia se hizo sentir fuertemente, ligado muchas veces a la importancia que las mujeres dieron a impulsar la educación confesional, a la cual consagraron sus esfuerzos, y a nuevas congregaciones católicas, extranjeras y nacionales (Munguía Escamilla, 2014, pp. 34-35). Según el Almanaque de Covarrubias de 1896, había al menos 13 escuelas confesionales privadas: el Colegio Convictorio Angelopolitano de San Luis Gonzaga, el Colegio Católico del Sagrado Corazón de Jesús, el Colegio de San Bernardo, el de la Santísima, el Moderno Instituto Católico. el de la Purísima, el Salesiano, el de San Luis Gonzaga, el de Santa Teresa de Jesús, el de San Vicente de Paul, el menor de San José de Gracia, el de la Providencia de San José de Gracia y el de San Alfonso. Surgidos entre las décadas de 1870 y 1880, respondían al interés de diversas corporaciones eclesiásticas o al patrocinio de algún clérigo. De hecho, hay dos tipologías en la fundación de estos colegios: eran fruto de congregaciones religiosas llegadas hacía poco a la ciudad y al país, o bien formaban parte de un interés del clero diocesano.

En uno u otro caso, el papel de las mujeres es fundamental en un contexto en el que la renovación del catolicismo se basó en buena medida en la labor de las congregaciones femeninas. En Puebla, por ejemplo, el Colegio Católico del Sagrado Corazón de Jesús o el Colegio Pío de Artes y Oficios, de los jesuitas, o el Colegio Salesiano, formado por los hijos de San Juan Bosco. Entre ellas destacan el de San Bernardo, fundado por el obispo Francisco Melitón Vargas, o el convictorio de San Luis Gonzaga, fundado por el canónigo José Victoriano Covarrubias. A esta nómina de colegios confesionales habría que sumar los dos colegios metodistas y ocho escuelas gratuitas de la Sociedad Católica, ubicadas en las zonas más pobres de la ciudad (Covarrubias, 1896, pp. 99-137). ${ }^{6}$ En este último

6 Las escuelas de la Sociedad Católica eran la Escuela del Corazón de María, en el exconvento de San Antonio; la del Corazón de Jesús, en la calle del Señor de los Trabajos; la del Santo Ángel, en el atrio de la Iglesia de Santo Ángel Analco y, en los diversos barrios de la ciudad, la de Santo Tomás, la de Nuestra Señora de Guadalupe, la de Nuestra 
sentido, la escuela de Nuestra Señora de Pontmain, dirigida por las señoritas Ávila y Oropeza, cubría también la atención a los niños pobres. Al hacerlo, cubría en Puebla las necesidades educativas que también apoyaron, por ejemplo, las Hermanas del Sagrado Corazón de Jesús, fundadas por José María de Yermo y Parres, quienes como congregación de consagradas se dedicó a educar a niñas pobres al tiempo que se dedicaba a enseñar artes y oficios (Rosas, 2012, pp. 51-52). Como dejan ver los dos ejemplos reseñados, las mujeres tuvieron un papel central en esta renovación de la presencia católica en Puebla, integrando a la ciudad y al país a aquella "feminización" de la religión que se vivió a fines del siglo XIX y principios del siglo xx (Langlois, 1985).

Si bien tenemos escasos datos sobre el funcionamiento escolar de la escuela de Pontmain, es posible aseverar que funcionó con éxito a lo largo de una década. Dedicada como hemos visto a enseñar primeras letras y doctrina cristiana gracias a la labor de dos señoritas poblanas bajo el cuidado del cura de la Torre, la escuela fue creciendo. Esto permitió que en 1895 se fundara la escuela preparatoria, y el 7 de marzo de 1897 la Escuela Normal para Maestras Católicas de Nuestra Señora de Pontmain. Se trató de un esfuerzo emprendido por las dos profesoras, quienes recurrieron a la ayuda de varias profesoras normalistas, entre quienes destacaron Norberta López, Dolores Paniagua, María Castillo y el profesor Adolfo Márquez. El clérigo Carlos María Parra se dedicó a dar las clases de religión (Memorias, 1984, pp. 92). Entre las materias destacadas estaban sicología, sociología, lógica, canto y francés, además de pedagogía y las materias de los planes de estudio de las escuelas básicas. Durante los primeros años de vida de la Normal de Nuestra Señora de Pontmain sostuvieron la escuela el padre de la Torre y el canónigo Vito Modesto Barreda. Las primeras profesoras se titularon en 1901; entre ellas estuvieron las religiosas Concepción Castellant y Gertrudis León (Memorias, 1984, pp. 93-94).

En los primeros años del siglo xx las profesoras y el padre de la Torre tuvieron especial interés en contar con los mejores instrumentos educativos. Así, por ejemplo, "por mediación de una sobrina del Padre de la Torre", la religiosa Sofía de la Torre, hermana de la Caridad residente en París, se recibió en la Normal "una buena dotación de material didáctico para la enseñanza". Lo más destacado fueron los laboratorios de química, física y biología, además de cajas de Safray para la enseñanza de ciencias físicas y naturales, además de una biblioteca especializada en ciencias y sociología. Además, las profesoras se especializaron en matemáticas,

Señora de la Luz, la de Nuestra Señora del Carmen y la de Santa Teresa de Jesús (Covarrubias, 1896, p. 135). 
contabilidad, antropología, física y química. Este esfuerzo fue cerrado en 1914, cuando la revolución constitucionalista clausuró la escuela normal, dejando sin embargo la escuela primaria en funcionamiento (Memorias, 1984, pp. 56-58 y 156-158).

Como se puede ver, a través de la educación la Escuela de Primeras Letras y la Escuela Normal de Nuestra Señora de Pontmain, clérigos y laicas encontraron un espacio educativo para ofrecer una propuesta de presencia y formación católica en la sociedad poblana. El éxito de la empresa permitió que éstas se proyectaran hacia el conjunto de la población local y, lo que es más, los recursos obtenidos permitieron que las religiosas optaran por materiales educativos que, llegadas de Europa, permitieran ofrecer los mejores avances científicos y tecnológicos en las disciplinas que enseñaban, sin que esto significara descuidar la enseñanza religiosa. El esfuerzo, de nueva cuenta, no era un esfuerzo aislado: en esos mismos años, la Universidad Católica Angelopolitana fomentó un encuentro entre fe y razón a través de la educación superior (Rosas, 2014). El esfuerzo, además, se sumó en la Escuela de Nuestra Señora de Pontmain a una característica de la labor católica de aquellos años: la educación gratuita de niñas pobres, a quienes también se les inculcó, en su respectivo nivel, una enseñanza que ligaba religión y educación elemental. En ese sentido, la escuela de Pontmain en Puebla permitió que los católicos encontraran en la educación nuevos ámbitos para proponer vías de acción social en la Puebla del porfiriato.

El tercer y último elemento ligado al culto de Nuestra Señora de la Esperanza en Puebla es la fundación de una congregación, que nació ligada al templo y a la escuela, gracias de nueva cuenta al esfuerzo del padre Luis de la Torre. De hecho, la escuela fue un caso interesante porque combinó la atención escolar a niños pobres con el hecho de ser un centro de estudios fundado por una congregación que, a diferencia de las extranjeras, estaba surgiendo en Puebla.

En efecto: junto con los elementos arriba señalados, el culto a Nuestra Señora de Pontmain en Puebla quedó ligado a la fundación de la Congregación que a partir de 1908 sería conocido como las Hijas de Santa María de Guadalupe, dedicadas a la educación de niñas y jóvenes. Las fundadoras fueron precisamente las dos maestras que establecieron la escuela de primeras letras, Rosario Ávila Campos y Dolores Oropeza y Neve, quienes habían decidido vivir una vida de castidad y consagración a Dios utilizando la escuela como medio. Así, la congregación surgió en 1888 como un grupo de Terceras carmelitas que decidieron vivir en comunidad bajo la dirección del padre de la Torre, consagradas a la escuela de primeras letras (Memorias, 1984, pp. 38-54). Además de recomendar las virtudes 
comunes a toda religiosa, la búsqueda del silencio y la frecuencia de los Santos Sacramentos, Oropeza recordaba a las religiosas "que el dedicaros a la educación" debía fortalecer y no hacer olvidar "el recogimiento y la unión con Dios", dedicando su vida a "un constante orar y trabajar" (Memorias, 1984, p. 56).

En 1890 el obispo Francisco Melitón Vargas erigió canónicamente la comunidad de Hermanas Terceras de Nuestra Madre Santísima del Monte Carmelo, de votos simples y dedicadas a la enseñanza. El padre de la Torre fungió como su fundador y director espiritual. Tras la censura de Vito Modesto Barreda y la revisión del canónigo Joaquín Vargas, en 1897 el obispo Perfecto Amézquita aprobó sus constituciones, ligadas al reconocimiento del Plan de Estudios de la Escuela de Nuestra Señora de Pontmain (Memorias, 1984, p. 74). Al año siguiente profesaron los votos temporales las ocho novicias carmelitas, reconocidas en la ciudad entonces como un "manojo de florecillas de Nuestra Señora de Pontmain".

Como se ve, la congregación que más tarde sería de Guadalupe y surgió ligada al culto a Pontmain formó parte de la renovación de la vida religiosa en el mundo contemporáneo, tomando como eje no sólo el carácter activo de las (nuevas) religiosas, sino precisamente su condición de mujeres. En esta "feminización" de la religión, las nuevas consagradas encontraron como vía de consagración ya no la vida de clausura, sino el trabajo en actividades como la asistencia social o, en este caso, la educación -labores típicamente femeninas durante el periodo que nos interesa (Langlois, 1985)-. En ese sentido, podemos aseverar que la congregación religiosa que surgió en la década de 1880 en Puebla ligada al culto del Pontmain fue parte de una renovación del catolicismo mexicano -y global- que llevó a las mujeres a una vida religiosa activa que buscó a Dios a través de servicios útiles a la comunidad en el siglo. Así, la devoción a Pontmain en Puebla quedó ligada a la renovación de la vida religiosa femenina y a la educación católica, pilares de la renovación eclesial en México y en general en el mundo católico.

La influencia del arzobispo Ramón Ibarra, quien tomó posesión de la diócesis en 1902 y al año siguiente se convirtió en el primer arzobispo de Puebla, llevó a que el instituto fuera erigido canónicamente ya no bajo la advocación de Pontmain, sino como Instituto de Hijas de Santa María de Guadalupe (Memorias, 1984, pp. 106-114). De hecho, el mitrado mismo

Las religiosas eran la fundadora Rosario Ávila Campos -Dolores Oropeza murió en 1896- y con ella Casiana Bermúdez Leana, Emilia Sandoval García, Adelaida Tezcucano Zárate, maría de Jesús Mendoza Pérez Munguía, Guadalupe Sagasti Vega, Trinidad Pérez Corte y Dolores Jiménez (Memorias, 1984, p. 100). 
fue quien solicitó al padre de la Torre que su congregación se pusiera bajo la advocación de la aparición del Tepeyac, como un modo de honrar una devoción propia. Una vez aceptado el cambio, el 8 de octubre de 1908 Ibarra y González aprobó las Constituciones de la Congregación Diocesana Angelopolitana de las Hijas de la Santísima Virgen de Guadalupe. El 12 de diciembre de ese mismo año la congregación se consagró a María de Guadalupe con una misa de comunión general presidida por el arzobispo (Memorias, 1984, pp. 118-121).

Como se ve, gracias a la influencia del arzobispo Ramón Ibarra y González la congregación que había surgido bajo la advocación de Nuestra Señora del Carmen y Nuestra Señora de Pontmain se transformó en un instituto religioso consagrado a la virgen de Guadalupe. Si bien el nombre del Colegio mantuvo a la devoción francesa vigente por algunos años, este cambio fue fundamental para que la devoción a Nuestra Señora de la Esperanza fuera decayendo poco a poco, cediendo su lugar a la virgen del Tepeyac -que había sido coronada en 1895, viviendo así una renovación en su culto que se expresó a través del impulso de la devoción guadalupana en todo el país, en buena medida gracias a las decisiones de la jerarquía eclesiástica. El fin de la presencia de Pontmain en Puebla, pues, se debe también a la decisión de las autoridades eclesiásticas, en particular del arzobispo Ibarra y González. A pesar del cambio de advocación, empero, el carisma de la congregación no cambió, dedicándose a la educación de los niños y a la vida activa. A la sombra de Pontmain, pues, había surgido no sólo una devoción, sino una activa vida cultual, una escuela católica y un instituto religioso femenino de vida activa que buscó nuevos espacios para la participación de los católicos en la sociedad mexicana entre el porfiriato y la revolución.

\section{Conclusiones}

La devoción a Nuestra Señora de Pontmain en Puebla, vigente entre 1876 y 1914, formó parte de un Nuevo Catolicismo que se expresó a través de nuevas devociones y nuevos mecanismos de laicos, clérigos y consagradas católicas para hacer presente al catolicismo en la sociedad liberal. A través del culto a Nuestra Señora de Pontmain, pues, el clero secular poblano impulsó y al menos un grupo de fieles poblanos expresaron y cobijaron sus afanes de participar activamente en la educación de la niñez, en el auxilio de los necesitados y en el desarrollo de una vida devocional más activa, sea a través del culto mismo o de la fundación de una nueva congregación. En suma, pues, la presencia de Nuestra Señora de Pontmain en Puebla es un episodio local de un proceso de renovación de la Iglesia 
y el catolicismo en la sociedad durante la segunda mitad del siglo XIX y principios del Xx, fechas que en México se corresponden con el porfiriato y el inicio del anticlericalismo posrevolucionario.

La devoción a Nuestra Señora de Pontmain fue difundida en México a través de traducciones y textos de divulgación católica entre 1876 y 1903, encontrando en Puebla y México las principales ciudades donde se difundió su culto. Se enfatizó el hecho de que era la aparición mariana más importante -ocurrió en 1871-, y que su mensaje central era un llamado a la oración en un contexto de guerra y de persecución del catolicismo. En México, en concreto, se insistió precisamente en que su aparición garantizaba la protección mariana en un contexto adverso a los católicos -derrotados a partir de 1867-y sobre todo, se le equiparó con la virgen de Guadalupe, mecanismo que garantizó su aceptación entre los católicos mexicanos.

Si bien diferentes estudios permitirían identificar la aceptación nacional de su culto, a nivel local fue evidente que estos elementos llevaron a una devoción muy promovida en las décadas de 1890 y 1900, gracias al interés que algunos actores eclesiásticos y un grupo de seglares consagradas tuvieron en ello. A partir de la fundación de un oratorio bajo su advocación en 1891, en Puebla su culto dio pie a tres elementos de renovación del catolicismo: el desarrollo de una amplia vida devocional en torno a ella, la fundación de una escuela de primeras letras y una normal que llevaron su nombre y una congregación religiosa diocesana femenina de vida activa que llevó su nombre hasta su erección canónica en 1908. A través de estos tres elementos, pues, el culto a la virgen de Pontmain en Puebla fue un resultado y un detonante del nuevo catolicismo en las sociedades locales de México.

Si parece haber tenido tanto éxito, ¿por qué el culto a la virgen de Pontmain se fue extinguiendo en Puebla a partir de 1908, al grado de que al final de la revolución había prácticamente desaparecido? Los dos principales factores fueron el anticlericalismo de la revolución mexicana, que en 1914 cerró el templo y despojó a la congregación de varios de sus bienes, y el interés del arzobispo Ramón Ibarra y González por fomentar el culto a Nuestra Señora de Guadalupe y consagrar el instituto religioso a esta advocación ya desde 1908. Así, fueron factores al interior de la propia Iglesia los primeros que llevaron a una lenta disminución de la presencia simbólica de Pontmain en Puebla, que culminaron con los cambios que trajo consigo la revolución mexicana. A pesar de que prácticamente ha quedado olvidada en la Angelópolis, la historia de Pontmain en aquella ciudad nos recuerda los afanes de algunos católicos mexicanos por encontrar un espacio en las sociedades locales entre el porfiriato y la revolución. 


\section{Referencias bibliográficas}

Adame Goddard, J. (1991)

El pensamiento político y social de los católicos mexicanos, 1867-1914.

México: Instituto Mexicano de Doctrina Social Cristiana.

Bautista García, C. A. (2006)

Dos momentos en la historia de un culto: el origen y la coronación pontificia de la virgen de Jacona (siglos XVIII-XIX). Tzintzun. Revista de Estudios Históricos, 43, pp. 11-32.

Bautista García, C. A. (2012)

Las disyuntivas del Estado y de la Iglesia en la consolidación del orden liberal. México, 1856-1910. México: El Colegio de México, Universidad Michoacana de San Nicolás de Hidalgo.

Bautista García, C. A. (2014)

La coronación pontificia de las imágenes marianas en México y la afirmación de la soberanía social de la Iglesia católica durante el porfiriato. En Y. Celaya Nández (coord.), Diálogos con una trayectoria intelectual: Marcello Carmagnani en El Colegio de México. México: El Colegio de México, pp. 343-383.

Carbajal López, D. (2017)

Entre concordancias, debates y paralelos: Francia en el discurso conciliador del doctor Agustín Rivera y Sanromán, 1876-1897. Historia Mexicana, LXVII, 1, pp. 295-340.

Carrión, A. (1897)

Historia de la ciudad de la Puebla de los Ángeles (Puebla de Zaragoza), tomo primero. Puebla: Tipografía de las Escuelas Salesianas de Artes y Oficios.

Ceballos Ramírez, M. (1991)

El catolicismo social: un tercero en discordia. Rerum Novarum, la "cuestión social" y la movilización de los católicos mexicanos, 18911911. México: El Colegio de México.

Chávez, G. (1896)

La aparición guadalupana demostrada por los últimos ataques de sus enemigos: observaciones sobre la Carta atribuida al Señor Don Joaquín García Icazbalceta. Guadalajara: Tipografía Católica de A. Zavala y Compañía.

Chávez, G. (1903)

El amigo católico de las niñas. Lecciones instructivas y edificantes, morales, doctrinales y recreativas, para uso de las escuelas católicas:

Méjico y Barcelona: Ramón de S.N. Araluce, editor.

Clark, C. (2003)

The New Catholicism and the European Culture Wars. En C. Clark y 
W. Kaiser (eds.), Culture Wars. Secular-Catholic Conflict in NineteenthCentury Europe. Cambridge: Cambridge University Press, pp. 11-46.

Covarrubias, L. F. (1896)

1er almanaque histórico y directorio general de Puebla, formado en vista de documentos auténticos y con la colaboración de varios literatos, por... Año de 1896. Puebla: Imprenta de la Escuela de Artes y Oficios.

Díaz Patiño, G. (2016)

Católicos, liberales y protestantes. El debate por las imágenes religiosas en la formación de una cultura nacional (1848-1908). México: El Colegio de México.

Dupanloup, M. (1876)

Estudio sobre la francmasonería. Puebla: Imprenta de Pastor y Compañía.

García Ugarte, M. E. (2010)

Poder político y religioso. México, siglo XIX, dos volúmenes. México:

Universidad Nacional Autónoma de México, Instituto de Investigaciones Sociales, Cámara de Diputados, Instituto Mexicano de Doctrina Social Cristiana, Miguel Ángel Porrúa.

Kaiser, W. (2003)

'Clericalism - that is our enemy!'. European Anticlericalism and the Culture Wars. En C. Clark y W. Kaiser (eds.), Culture Wars. SecularCatholic Conflict in Nineteenth-Century Europe. Cambridge: Cambridge University Press, pp. 47-76.

Lafond, C. (1876).

Nuestra Señora de la Esperanza de Pontmain. Puebla: Imprenta Católica.

Langlois, C. (1985).

Le catholicisme au féminin. Les congrégations françases à supèriure générale au XIXe siècle. Paris: Cerf.

Leicht, H. (1999)

Las calles de Puebla Estudio histórico. Puebla: Gobierno del Estado de Puebla, Secretaría de Cultura, Ayuntamiento de Puebla.

Memorias (1984)

Memorias de la Congregación de las Hijas de Santa María de Guadalupe, primera parte. Puebla: edición para uso privado.

Mendizábal, J. (1894)

Sexto almanaque de efemérides del Estado de Puebla, arreglado al meridiano de su Capital para el año de 1894. México: Tipografía del Círculo Católico. 
Mendizábal, J. (1900)

Noveno almanaque de efemérides del Estado de Puebla, arreglado al meridiano de su Capital para el año de 1900. Puebla: sin editor.

Mendizábal, J. (1904)

$13^{\circ}$ Almanaque de efemérides del Estado de Puebla, arreglado al meridiano de su Capital para el año bisiesto de 1904. Puebla: Imprenta del Convictorio Angelopolitano.

Mendizábal, J. (1905)

Decimocuarto almanaque de efemérides del Estado de Puebla, arreglado al meridiano de su capital para el año de 1905. Puebla: tipografía del Convictorio.

Mendizábal, J. (1908)

$17^{\circ}$ Almanaque de efemérides del Estado de Puebla, arreglado al meridiano de su capital para el año bisiesto de 1908. Puebla: tipografía del Convictorio.

Mendizábal, J. (1909)

18ํA Almanaque de Efemérides del Estado de Puebla, arreglado al meridiano de su capital para el año de 1909. Puebla: oficina tipográfica del Arzobispado.

Mendizábal, J. (1910)

19․ Almanaque de efemérides del Estado de Puebla para el año de 1910. Primer centenario de la proclamación de la Independencia Nacional. Puebla: oficina Tipográfica del Arzobispado.

Moreno Chávez, J. A. (2013)

Devociones políticas: cultura política y politización en la Arquidiócesis de México, 1880-1920. México: El Colegio de México.

Munguía Escamilla, 2014.

Influence de l'education française au Mexique: L'ouvre regionale des collèges et des immigrants-professeurs/instituteurs au XIXe siècle. En J. Pérez Siller y J.M. Lassus (dirs.), Les français au mexique. XVIIIeXXIe siècle, volumen 2. Savoirs, réseaux et représentations. París: L'Harmattan, Université de Nantes, Benemérita Universidad Autónoma de Puebla, pp. 15-40.

Nicolás, A. (1876)

El Estado sin Dios. Puebla: Imprenta de J. M. Pastor y Compañía.

O’Dogherty Madrazo, L. (2003)

De urnas y sotanas. El Partido Católico Nacional en Jalisco. México:

Consejo Nacional para la Cultura y las Artes, Universidad Nacional Autónoma de México.

Porte, C. A. (2005)

Pontmain, Prophecy and Protest: A Cultural-Historical Study of a Ni- 
neteenth-Century Apparition. Nueva York: Peter Lang Publishing Incorporated.

Revista, 1868.

La Revista Eclesiástica, I. Puebla: Imprenta del editor, dirigida por Isidoro Boclar.

Romero de Solís, J. M. (2006)

El aguijón del Espíritu: historia contemporánea de la Iglesia en México, 1892-1992. México: Instituto Mexicano de Doctrina Social Cristiana, El Colegio de Michoacán, Archivo Histórico del Municipio de Colima, Universidad de Colima.

Rosas, S. (2012).

El Círculo Católico de Puebla, 1887-1900. Estudios de Historia Moderna y Contemporánea de México, 43, pp. 35-67.

Rosas, S. (2014)

Educación y Nuevo Catolicismo en México. La Universidad Católica de Puebla, 1906-1914. Itinerantes. Revista de Historia y Religión, 4, pp. 189-207.

Wright-Rios, E. (2009)

Revolutions in Mexican Catholicism. Reform and Revelation in Oaxaca, 1887-1934. Durham: Duke University Press. 